\title{
Study on Human Temperature Measurement by Infrared Thermography ${ }^{\dagger}$
}

\author{
Michal Švantner *(D), Vladislav Lang ${ }^{\mathbb{D}}$, Tomáš Kohlschutter, Jiří Skála, Milan Honner, Lukáš Muzika \\ and Eliška Kosová
}

check for

updates

Citation: Švantner, M.; Lang, V.; Kohlschutter, T.; Skála, J.; Honner, M.; Muzika, L.; Kosová, E. Study on Human Temperature Measurement by Infrared Thermography. Eng. Proc 2021, 8, 4. https://doi.org/10.3390/ engproc2021008004

Academic Editors: Giovanni Ferrarini, Paolo Bison and Gianluca Cadelano

Published: 17 November 2021

Publisher's Note: MDPI stays neutral with regard to jurisdictional claims in published maps and institutional affiliations.

Copyright: (c) 2021 by the authors. Licensee MDPI, Basel, Switzerland. This article is an open access article distributed under the terms and conditions of the Creative Commons Attribution (CC BY) license (https:// creativecommons.org/licenses/by/ $4.0 /)$.
New Technologies-Research Centre, University of West Bohemia, 30100 Plzeň, Czech Republic; vlang@ntc.zcu.cz (V.L.); kolsi@ntc.zcu.cz (T.K.); jskala@ntc.zcu.cz (J.S.); honner@ntc.zcu.cz (M.H.); muzika@ntc.zcu.cz (L.M.); kosovael@students.zcu.cz (E.K.)

* Correspondence: msvantne@ntc.zcu.cz

+ Presented at the 16th International Workshop on Advanced Infrared Technology \& Applications, 26-28 October 2021; Available online: https:/ / aita2021.sciforum.net/.

\begin{abstract}
Increased temperature in humans is one of symptoms of infectious diseases. Infrared thermography is a popular method for measuring temperature as it offers fast and non-contact temperature measurement. However, and despite many advantages, its real accuracy for human temperature measurement is not sufficient in many cases. This study was focused on a statistical evaluation of human temperature measurement reliability. The goal of the experiment was to find limitations of thermography at near-laboratory conditions. More than 300 measurements were made simultaneously by a thermography and an arm-pit thermometer on a closed group of persons during several months. The results showed that standard deviations of the performed armpit and thermographic temperature measurement were about 0.15 and $0.36^{\circ} \mathrm{C}$, respectively, but that a temperature shift and a dependence on ambient conditions can occur due to the used experimental configuration.
\end{abstract}

Keywords: thermography; human temperature measurement; thermographic measurement

\section{Introduction}

Increased core temperature or fever in humans is a manifestation of many infectious diseases. Thus, human temperature diagnostics has been assumed as a useful diagnostic method for an indication of these diseases [1]. The basic quantity is core temperature, which refers to the body's internal organs. Normal human temperature is influenced by various effects. However, it is usually $36-36.9^{\circ} \mathrm{C}$ (differences based on a source), an increased temperature is considered $37-38{ }^{\circ} \mathrm{C}$ and a fever is more than $38{ }^{\circ} \mathrm{C}$.

Core temperature can be measured by invasive medical procedures in a hospital. A peripheral body temperature (that is, a 'skin level' temperature) can variate significantly based on a location, health, or ambient conditions. It can be measured by many noninvasive methods in the mouth, ear (tympanic), armpit or rectum. However, a correlation should be carried out to estimate core temperature. Procedures of use, equipment requirements, and interpretation of results for these methods are described (e.g., in standard [2] or in publication by Moran and Mendal) [3]. These methods are mostly not suitable for a screening due to their contact nature or technical impracticability in public spaces. Thus, infrared (IR) non-contact methods have been developed and applied for human temperature diagnostics. They have been used in medical applications [1,4] for many years, such as for diagnostics of inflammations, diabetic diseases, or in dentistry (and many other). It is very effective for a qualitative thermography (temperature or contrast differences are sufficient). However, human temperature diagnostic is a quantitative thermography with high demands for an absolute accuracy about $\pm 0.1{ }^{\circ} \mathrm{C}[3,5]$. The measurement is non-contact, fast, and can be carried out at a safe distance in public spaces as well. Its disadvantages are that only skin temperature is measured [6] and that most IR cameras 
have an insufficient accuracy. Despite these drawbacks, IR methods have been developed and applied for screening purposes during infectious epidemics (for example, after the SARS epidemic in 2002 [7,8], after the H1N1 epidemic in 2009 [9], or after MERS-CoV (2012) and Ebola (2014) [10].

IR thermography can be a useful tool if the measurement is performed in accordance with relevant standards [5]. Still unsatisfying, however, is the mass implementation and interpreting of the results, since the standards prescribed in detailed measurement conditions (devices accuracy, environment, measurement configuration etc.) are often difficult to comply with in practical use. This study was focused on an experimental determination of the limits of human body temperature measurement. Studies about technical limits of IR cameras, their effectiveness in fever patients' detection, or their usage in public spaces have already been published. In contrast to these studies, this study was focused on the long-term measurement of a closed group of persons. The experiment was conducted in the course of several months and each measurement was made using an IR camera and armpit thermometer together. The goal was not to find persons with an increased body temperature. The aim was to statistically evaluate and confirm mean values and total variance of human body temperature measurement on a healthy group of testers. The variance is, in this case, caused by devices uncertainty as well as differences during measurement or human body natural scatters between both individuals and for one person over time. It should be thus rather relevant to a real application than a precisely guided experiment.

\section{Experimental Procedure}

The experiments took place inside a building since November 2020 to March 2021. A FLIR A315 IR camera (resolution $320 \times 240$ pixels, thermal sensitivity/NETD $<0.05^{\circ} \mathrm{C}$ at $+30{ }^{\circ} \mathrm{C}$, accuracy $\pm 2{ }^{\circ} \mathrm{C}$ or $\pm 2 \%$ of reading) with $25 \mathrm{~mm}$ lens was used with a Kleiber KBB 40 black body (reference temperature $40{ }^{\circ} \mathrm{C}$, emissivity $0.98 \pm 0.004$, aperture $50.8 \mathrm{~mm}$, temperature uncertainty $0.4{ }^{\circ} \mathrm{C}$, repeatability $0.2{ }^{\circ} \mathrm{C}$, stability $0.1{ }^{\circ} \mathrm{C}$ ) for the thermographic measurement. The measurement was made with the emissivity 0.98 set on the IR camera. The measurement system was located in a room at standard-office non-controlled conditions. An electronic thermometer Microlife MT850 (accuracy $\pm 0.1^{\circ} \mathrm{C}$ ) was used for an armpit body temperature measurement.

During the period of the experiment, test persons (testers) repeated the measurement periodically. The group of testers consisted of staff members working in the building and arbitrary visitors. The group was a mix of men and women. However, as the measurement was strictly anonymous, it was not registered a ratio of man and women or a frequency of individual testers measurement (some of testers performed the measurement more often than others).

The IR camera and the reference black body (BB) were at a fixed position in such a way that the BB was always in a field of view of the camera in a distance about $100 \mathrm{~cm}$ and took about $2 \%$ of a recorded scene. Each tester was instructed about the measurement procedure and made the measurement on their own. A tester took a specified position in the field of view of the IR camera (at distance about $100 \mathrm{~cm}$ ) near the BB so that his face occupied about $30 \%$ of the scene. A non-reflective fabric surface was in the background of the scene. A thermographic image was recorded and saved automatically after a control software recognized the tester in a specified position. The tester subsequently performed and registered a body temperature measurement by the armpit thermometer. The testers were instructed to perform the measurement at the earliest after a 30-minute stay in the building to be tempered, without a face mask and glasses and not immediately after eating, drinking, face washing, etc. However, other conditions (e.g., an ambient temperature of a place of previous stay or activity) were not registered or specified. 


\section{Results}

In total, 323 valid records were obtained during the testing period. Each infrared image was processed manually and maximum face temperature, location of the maximum temperature, BB temperature, and background temperature were evaluated and analyzed together with the armpit body temperature.

Micro-bolometers based thermographic devices are often influenced by ambient temperature. In this case, ambient temperature variation was estimated by background temperature variation measured by the IR camera. The mean value of the background was $22.91^{\circ} \mathrm{C}$ with the standard deviation (StDev) $1.14{ }^{\circ} \mathrm{C}$ and it varied in the interval $20.09-28.33{ }^{\circ} \mathrm{C}$. Regression analysis of dependence of the uncorrected face maximum temperature on the armpit temperature (APT) and the background temperature (BGT) showed significance of both these variables ( $p$-value $<<0.05$ ). Regression coefficients were 0.57 and 0.21 for APT and BGT, respectively. That indicates a big influence of both variables. After a correction of the face maximum temperature according to the black body temperature, the coefficients changed to 0.55 and 0.08 for APT and BGT, respectively. Although BGT still has an effect, this result indicates a decreasing of its significance regarding the APT.

The mean value of uncorrected face maximum temperature was $35.55^{\circ} \mathrm{C}$ (StDev $\left.0.43{ }^{\circ} \mathrm{C}\right)$ and it changed to $35.70{ }^{\circ} \mathrm{C}\left(\mathrm{StDev} 0.36^{\circ} \mathrm{C}\right)$ after the $\mathrm{BB}$ correction. The mean value of the APT was $36.29^{\circ} \mathrm{C}$ ( $\mathrm{StDev} 0.15^{\circ} \mathrm{C}$ ). It is evident from Figure 1 that the BB correction decreased dependence on ambient conditions, decreased the standard deviation, and slightly increased the mean value of the maximum face temperature. However, the mean value is still significantly smaller than the APT mean. This discrepancy can be caused by several factors. Especially significant can be insufficient resolution, small ratio of an area of the scene occupied by the face (background influence), and physiological reasons. It should be noted as well that the APT has some scatter and some outliers can be registered. This variance is caused by natural differences (between testers and in course of time of individual testers) as well as by a non-perfect APT measurement due to a self-measurement. However, this variation is significantly smaller compared to face temperature measurement.

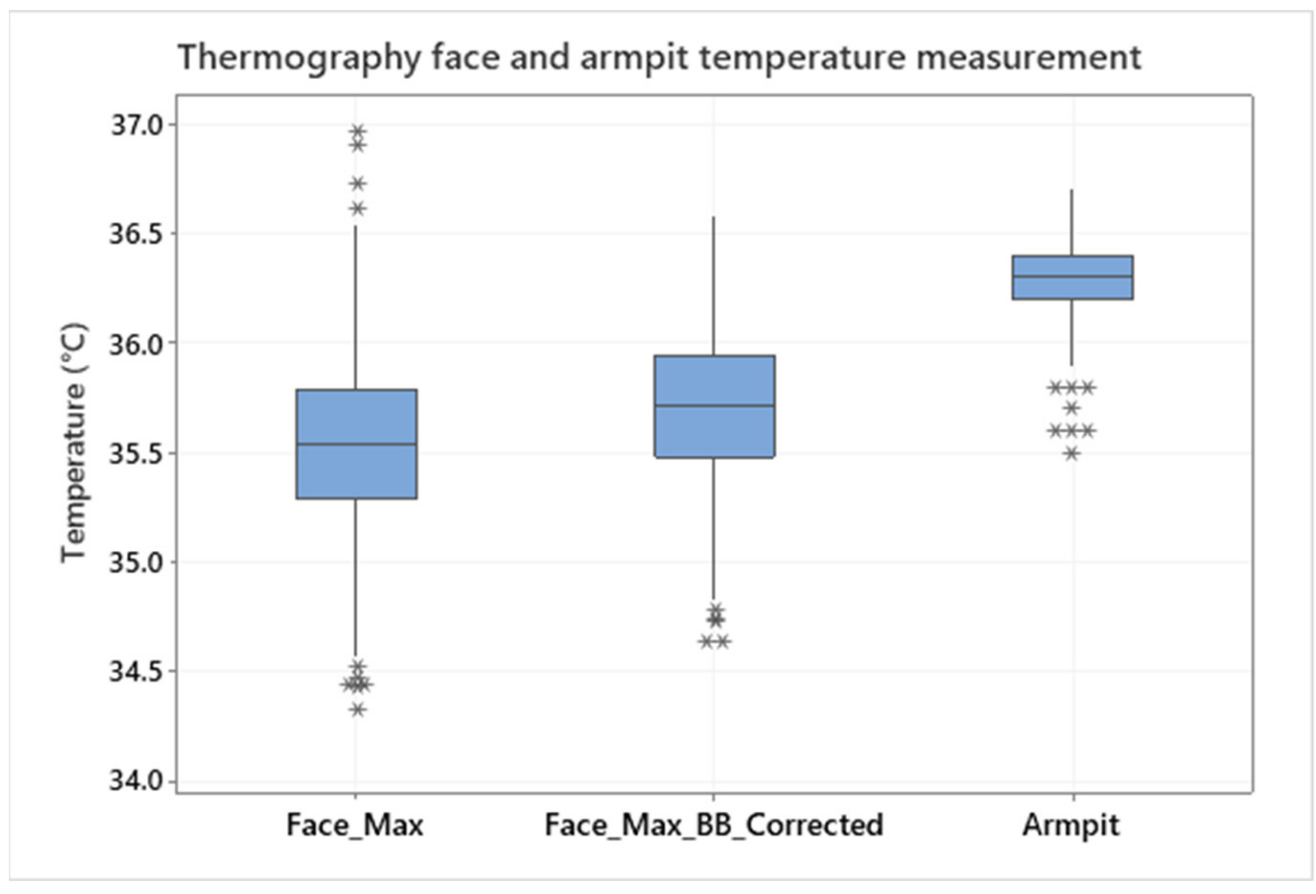

Figure 1. Boxplot of the mean values of the uncorrected face maximum temperature, face maximum temperature after BB correction, and armpit temperature (symbols * show outliers). 
The maximum face temperature should be related to the eyes' inner canthi (a corner of the eye where the upper and lower eyelids meet), which should be comparable with the APT. An analysis of the obtained results however showed that $83.3 \%$ of values were related to the inner canthi, $8.1 \%$ to a neck location, $4.1 \%$ to mouth region, and the rest to other face locations (11 locations, 1 or 2 values register for each one). This can be caused by external factors or by minor injuries or inflammations in the face region. Significant differences between the inner canthi and other positions for maximum face temperature were not observed. However, if the temperature of the inner canthi would be strictly required, this fact should be taken into account and a face maximum temperature in the eyes' canthi cannot be assumed.

\section{Conclusions}

More than 300 testers were measured over the several months-long period by the IR camera and armpit thermometer. An elevated body temperature was identified in none of the testers. Despite quite stable conditions, an influence of ambient conditions was identified, which could be reduced by a black body calibration. Even if the black body reference was used, the face maximum temperature was about $0.6^{\circ} \mathrm{C}$ lower compared to the armpit temperature. This can be the result of both physiological and technical reasons. The accuracy of the used black body is $0.4{ }^{\circ} \mathrm{C}$, and thus the IR measurement can be deviated even if it is BB corrected. Other uncertainties sources are related to measurement configuration. The used one allowed for self-testing and corresponded to too many practically used configurations of an IR screening. Insufficient resolution and ratio of the face area in the scene (should be about 70\%) can cause such a shift of the measured mean, and it is necessary to take this fact into account. Finally, the standard deviation of the face maximum temperature measurement (BB corrected) is $0.36{ }^{\circ} \mathrm{C}$. As the measurement was performed at the half-laboratory conditions with instructed testers, this can be assumed as an accuracy limit and, even if the $95 \%$ confidence intervals for the means were quite narrow (35.66-35.74 ${ }^{\circ} \mathrm{C}$ for face maximum temperature after $\mathrm{BB}$ correction), some number of outliers should be always expected.

Funding: The work was supported by Ministry of Education, Youth and Sports of the Czech Republic within the ERDF project "LABIR-PAV/Pre-application research of infrared technologies" Reg. No. CZ.02.1.01/0.0/0.0/18_069/0010018 and by the Ministry of Interior of the Czech Republic within the project No. VI04000029 of the "Security Research Programme of the Czech Republic in the years 2015-2022".

Conflicts of Interest: The authors declare no conflict of interest.

\section{References}

1. Lahiri, B.B.; Bagavathiappan, S.; Jayakumar, T.; Philip, J. Medical applications of infrared thermography: A review. Infrared Phys. Technol. 2012, 55, 221-235. [CrossRef] [PubMed]

2. Czech Standards Institute. Ergonomics_Evaluation of Thermal Strain by Physiological Measurements; Standard No. ČSN EN ISO 9886; International Organization for Standardization: Geneva, Switzerland, 2004.

3. Moran, D.S.; Mendal, L. Core Temperature Measurement. Sports Med. 2002, 32, 879-885. [CrossRef] [PubMed]

4. Ring, E.F.J.; Ammer, K. The technique of infrared imaging in medicine, Infrared Imaging A Caseb. Clin. Med. 2015. [CrossRef]

5. Czech Standardization Agency. Medical Electrical Equipment-Part 2-59: Particular Requirements for Basic Safety and Essential Performance of Screening Thermographs for Human Febrile Temperature Screening; Standard No. ČSN EN IEC 80601-2-59; International Electrotechnical Commission (IEC): Geneva, Switzerland, 2019.

6. Kim, D.W.; Zhang, H.Y.; Yoo, J.H.; Park, Y.S.; Song, H.J.; Yang, K.H. The correlation between tympanic membrane temperature and specific region of face temperature. Quant. Infrared Thermogr. J. 2019, 16, 1-7. [CrossRef]

7. Ng, E.Y.K.; Kawb, G.J.L.; Chang, W.M. Analysis of IR thermal imager for mass blind fever screening. Microvasc. Res. 2004, 68, 104-109. [CrossRef] [PubMed]

8. Chiu, W.T.; Lin, P.W.; Chiou, H.Y.; Lee, W.S.; Lee, C.N.; Yang, Y.Y.; Lee, H.M.; Hsieh, M.S.; Hu, C.J.; Ho, Y.S.; et al. Infrared thermography to mass-screen suspected sars patients with fever. Asia-Pac. J. Public Health 2005, 17, 26-28. [CrossRef] [PubMed]

9. Nishiura, H.; Kamiya, K. Fever screening during the influenza (H1N1-2009) pandemic at Narita International Airport, Japan. BMC Infect. Dis. 2011, 11, 111. [CrossRef] [PubMed]

10. Cosford, P. Airport screening for Ebola: Advantages of airport screening for Ebola. BMJ 2014, 349, 6585. [CrossRef] [PubMed] 